\title{
Academic Writing in an ODL Context: Perceptions and Experiences of First Year University Students
}

\author{
Jack M. Chokwe
}

Department of English Studies, University of South Africa chokwmj@unisa.ac.za

\section{Doi:10.5901/mjss.2013.v4n3p535}

\begin{abstract}
The study aimed to examine first year students' conceptions of writing and the extent to which these conceptions influence their academic writing and suggest guidelines that can inform effective teaching and learning of writing in ESL contexts. The study is underpinned by the academic literacies model and adopted a qualitative research methodology and used a case study approach. Participants included ESL first year students and tutors. Questionnaires, focus group interviews and marked student writing samples were employed as data collection instruments. Though students claimed that they subscribed to the ideologies of the academic literacies model, and that the first year level course improved their academic writing, the findings show that, on the contrary, students were underprepared for engaging in the academic writing activities required at university level. Moreover, the findings showed that students categorised their writing skills as average. The findings reveal that tutors found that students still struggle with aspects of writing including, for instance, grammar, spelling, the structuring of essays, coherence and cohesion in paragraphs as well as arguing a point convincingly.
\end{abstract}

Keywords: Open Distance Learning, academic literacy, academic writing, under-preparedness.

\section{Introduction}

Research shows that student writing is, and continues to pose challenges for English Second Language (ESL) teaching and learning contexts across the globe, in particular, in higher education institutions (Lillis and Scott 2007; Ivanic and Lea 2006; Lea 2004; Munro 2003; Lea and Street 1998; Gambell 1991). On the international front, particularly in the United Kingdom (UK), in noting the relationship between writing and literacy, Lea and Street (1998:157) report that literacy standards in schools and higher education institutions are very low and academics often complain that students cannot write properly. Munro (2003:327) confirms this view and argues that dealing effectively with students' literacy difficulties and in turn, poor academic writing skills, is a challenge that universities across the world have to contend with.

In South Africa too, there are growing concerns about the high levels of poor student writing in schools and higher education. Recent media reports show that students entering higher education are struggling to write effectively and are therefore under-prepared for studies in institutions of higher learning (News24 30/06/2009 ${ }^{1}$; Kgalema Motlanthe, 22/04/2010). Several studies in South Africa confirm these reports and have identified some factors that tend to influence and impact negatively on student writing. These include students' low literacy levels and under-preparedness (Van Schalkwyk, Bitzer and van der Walt 2009; Moutlana 2007; Banda 2007; Niven 2005), students learning in a second, third or fourth language (Banda 2007; Jacobs 2005; Van Rensberg and Lamberti 2004), and lecturers and tutors adopting inadequate approaches in teaching academic writing (van Schalkwyk et al 2009; Moutlana 2007; Bharuthram and McKenna 2006; Boughey 2000). These factors are pertinent to the South African context and are discussed further below.

Various research studies indicate that ESL students tend to be under-prepared for university studies (Cliff and Hanslo 2009:274; Granville and Dison 2009:56 Hirst, Henderson, Allan, Bode and Kocatepe 2004:74; Schwartz 2004:27; Maloney 2003:664; Boughey 2000:281). Under-prepared students find it difficult to cope with the writing tasks that are expected of them in higher education teaching and learning contexts (Cliff and Hanslo 2009:274; Van Rensberg and Lamberti 2004:68; Maloney 2003:664). As a result, their experiences of academic writing tasks tend to be negative.

These studies show that there is a strong link between student writing difficulties and under-preparedness. Niven

\footnotetext{
1 This is an online news report
} 
(2005:774) attributes the problems of under-prepared students' experience with writing at university to the wide gap between writing expectations and demands between school and university. This means that universities should expect first year students to be inadequately prepared for the required writing skills because as Hirst et al. (2004:66) confirm, students were not equipped to deal with the academic or tertiary literacies required of them. Therefore, universities should be expected to put in place proper structures that can support under-prepared students to start addressing and improving their specific academic writing needs.

In examining the literacy levels in South Africa, Moutlana (2007:2-3) argues that the low literacy standards among students should be an issue of concern in education circles and ascribes the low literacy standards among South African students to student under-preparedness at various levels. Furthermore, he points out that learning problems within institutions will not disappear until language proficiency and academic literacy occupy a central place in tertiary institutions (Moutlana, 2007:3). Similarly, Banda (2007:2) concedes that it is public knowledge that ESL students often have difficulties with academic writing and argues that low literacy levels have a strong link to students' underpreparedness for higher education studies. It is clear that both factors, that is, students' low literacy levels and underpreparedness can impact negatively on students' writing competencies, and in turn their ability to succeed in their studies. However, under-preparedness is not only a student problem but a staff problem as well because lecturers and tutors also seem unprepared and at times reluctant to address first year students' inadequate writing skills.

\section{Theoretical Framework}

The study is underpinned by the academic literacies (AL) approach. This approach is appropriate for examining students' conceptions of writing because 'it identifies writing as a social and disciplinary process' (Lillis 1999:26). The AL approach focuses on reading and writing within the disciplines (Lea and Street 1998:369). Thus, proponents of the academic literacies view writing as a communicative act which involves the sharing of observations, information, thoughts, or ideas with students themselves and others (Cohen and Riel 1989:143). The AL approach confirms Jurecic's (2006:1) contention that writing is not a formula or a series of exercises that can be drilled and corrected but it is an unruly process in the teaching and learning process.

The AL model recognises and acknowledges that the student's background is critical and core to teaching and developing academic writing at university. Students' perceptions and experiences of writing in ESL contexts are of importance because such insights can contribute to a better understanding of why students continue to struggle with their writing and inform institutions of higher learning on effective ways of developing and improving students' writing competencies (Lafaye and Tsuda 2002:156). In addition, Lea and Street (1998) argue that treating students as collaborators in the writing process and development of academic literacies is a necessary activity that universities should engage in.

The AL model also challenges lecturers and tutors to reflect on their practice in academic writing and foreground many dimensions to student academic writing which include the impact of power relations on student writing; the centrality of identity; academic writing as ideologically inscribed knowledge construction and the nature of generic, academic as well as discipline specific writing practices (Lillis 2003:195). As a result, the theory takes a holistic approach to writing and examines ways in which current models and practices may need to be adapted in order to accommodate the changing culture of higher education. In other words, the AL approach encapsulates the strengths of the study skills and academic socialisation models. In arguing for the incorporation of AL model by tutors and lecturers, Hirst et al (2004:66) propose the adoption of the contextually-based approach which involves the introduction of students to the conventions and genres of particular disciplines as an integral part of teaching within that discipline. In addition, Boughey (2000:281) argues that literacy is not something that can be overtly taught in a convenient series of lectures but through observing and interacting with the members of the discourse until their ways of speaking, acting, thinking and valuing common to that discourse become natural to them.

\section{The Method}

This study adopted a qualitative research methodology because 'it aims to better understand human behaviour and experience' (Bogdan and Biklen 2007:43). Qualitative researchers believe that approaching people with the goal of trying to understand their point of view can bring about deeper insights and understandings of the informants' experiences (Bogdan and Biklen 2007:26). A qualitative paradigm is of importance in this study because it seeks to understand perceptions of ESL students and tutors regarding academic writing. 


\subsection{The Context}

Context includes the geographical environment or the setting under which a study takes place. It is vital to understand the setting of the ESL participants in order to find solutions to the academic writing challenges that they face. This study investigates the perceptions and experiences of ESL first-year university English students and tutors toward academic writing at the University of South Africa (Unisa), which is based in the City of Tshwane/Pretoria in South Africa. Unisa is the largest Open and Distance Learning (ODL) university in Southern Africa and had over 300000 students registered in 2011. As an ODL university, Unisa operates at a distance and students are able to learn wherever they are without any geographical or time constraints. Learning is also flexible as students are able to learn at their own pace.

Student support at Unisa, amongst others, includes tutorial classes done by tutors at regional offices, discussion classes which are done once a semester by lecturers, Academic Literacies Centres which are responsible for teaching and training students in academic writing, and myUnisa which is an online learning management system. So, Unisa provides additional support through tutorial classes which are offered by tutors appointed by the Tutorial Support and Discussion Classes (TSDL) department as well as academic writing support by the Academic Literacies Centres. Currently, some TSDL tutors offer tutorials and are also involved in assessing students as tutor-markers. However, this intervention is still in its pilot phase and the tutor-markers who participated in this study do not have face to face contact with students but provide marking services as external markers who are in a way also involved in tutoring as they assess and provide valuable feedback to students. Therefore, tutor-markers are referred to as tutors in this study. The students come from different schooling backgrounds with some being employed and some being 'full time' students.

In addition, Unisa students have been provided with myUnisa which is an online learning management system used for teaching and learning. This system can be accessed by any registered student anywhere in the world through the internet. Amongst other features, the system has study materials, discussion forums, announcements, additional study material and self assessment tasks. However, some students, particularly those in rural areas have a challenge of staying too far from the regional offices to access myUnisa and there are costs implications involved. Some still need to be computer literate for them to be able to participate in online learning. As a result, these challenges must be taken cognisant of, especially in ensuring that ESL learners are taught academic writing through online learning.

Despite having a limited number of English first language students, Unisa is an appropriate university for this study because the student population comprises ESL students who are expected to do extensive academic writing for their studies. Furthermore, Unisa students are mainly based in Southern Africa and other parts of Africa and sporadically spread across the world. Arguably, Unisa is one of the largest ODL universities in the world.

ESL first year students who are registered for English for Academic Purposes (ENN103-F) were selected to participate in the study. This module is referred to as a fundamental module, which means, it has to provide students with the critical skills that are required for them to succeed at university. The ENN103F module focuses on developing students' academic reading and writing skills in the English language. English is the medium of instruction at Unisa. As a result, the course is enrolled by students doing various qualifications in Colleges of Human Sciences, Education, Economic and Management Sciences, Agriculture and Natural Sciences as well as Engineering, Science and Technology at this ODL institution. Most of these students are second or third language speakers of English. Although aimed at first year students fresh from high school, the course expects that students should have acquired several skills outlined below:

- Students admitted to this module must have passed a National Qualifications Framework (NQF) level 4 English and they are assumed to be capable of reading extended texts, comprehending the main ideas and following a line of argument,

- They are expected to be able to read a number of texts on a related topic and collate the ideas, and

- They are also expected to write extended discursive/ argumentative texts that focus on a given topic, using an introduction, body, and conclusion structure (Unisa 2002).

\subsection{Data Collection}

In this study, a student questionnaire was distributed through an online learning management system (myUnisa) to student e-mails as well as face-to-face to the Gauteng Regional Office. In addition, the questionnaire was distributed after two tutorial sessions on the $04^{\text {th }}$ and $14^{\text {th }}$ August 2011 to two groups of students. Of the 48 questionnaires, 33 questionnaires were completed by students who were attending tutorials while 15 were completed by students who responded to online questionnaires distributed through myUnisa which students returned through e-mail. Online respondents signed the consent form manually and scanned it while some just typed their names. 


\subsection{Student sample}

The sampling process involved several stages. In the first instance, first year students registered for English for Academic Purposes (ENN103F) module were selected. Secondly, only ESL speakers were selected to participate in the study. The study population comprised of 48 students who were purposefully and conveniently chosen to participate in the study. Only 15 of these students were involved in focus group interviews because they consented to participate in the study after the Saturday tutorial class. A small sample was deemed necessary in order to make the data more manageable (Fossey, Harvey, Mc Dermott and Davidson, 2002:726). These students were those who attended Tutorial Support and Discussion Classes (TSDL) tutorials and were conveniently accessed after the tutorial class. They were willing to participate after the study was explained to them.

\section{Results}

Some students mentioned that they were not prepared adequately for the writing demands required at university while some felt they were well prepared for the writing demands at university. Participants clearly indicated that they struggled with the structuring of their essays. Debora stated that she was not ready for academic writing required at university "because I am struggling when it comes to the introduction and conclusion in writing" while Nancy commented that "I find it difficult to write the essay like in a very good was doing all the three structures of an essay". On the contrary, Jacqui mentioned: "Yes, we are able to supply what is needed when you write essay must have introduction, body and conclusion". Interestingly, Kwena explicitly said that: "The essay must have an introduction which pulls the attention of a reader, the body where you you're your story or your thoughts about de ${ }^{2}$ topic and lastly the conclusion where you summarise the whole essay. You can call it a solution".

In one instance, the findings reveal that students claimed to have been well prepared to write essays. However, an analysis of the written essay indicated that students were still struggling and had problems structuring their writing. This finding corroborates assertions that writing is one of ESL first year students' main weaknesses (Cliff and Hanslo 2009; Van Schalkwyk et al. 2009; Lamberg 1977).

Although in some instances the findings show that participants indicated that writing coherently was not a problem, these students struggled with "organisation of ideas" (John) and "to know how to arrange my arguments, differentiate an essay and a thesis and arrange my paragraphs as expected" (Esther).

The findings show that students realised that they required assistance in writing paragraphs in addition to addressing the surface grammar errors and it is a serious concern which participants acknowledged about their weaknesses in academic writing. Again, this finding supports Nunan's (1990) argument that learners' inputs should also be considered in curriculum design as they are aware of their weaknesses. Writing coherently is also a critical and very important component of academic writing because in most cases students have relevant ideas which are not well organised. This also suggests that ESL practitioners should teach this component.

The findings on students' perception on what constitutes good quality academic writing indicated their understanding of good writing included few or no grammar mistakes, the structure (that is, the introduction, body, and conclusion) as well as coherence. These responses resonate with Anokye's (2008) definition of good writing as well as tutor responses. For instance, John commented that writing is good "if your spelling is correct and not mixing points and originality". Similarly, David mentioned that good writing has "no spelling errors and the sentence construction is good and that it is "any writing with good spelling". In addition, Jane concurs that good writing "must have organized ideas, good grammar and less spelling errors".

The findings reveal that respondents thought the word "revising" meant preparing for exams. However, it was explained further in focus group interviews. Perhaps, this is also an indication that they were not familiar with the writing process. However, some answered the questions within the right context. Some participants also indicated that they indeed revise their work as part of the writing process. One participant indicated that "I check for spelling errors, grammar and organization of ideas" (Lesiba) and the other one said: "I usually read through the neat work and try to change anything except the spelling and maybe add something here and there. I do not like changing anything because I will change the whole story line when beginning to make changes (Martha) while another one explained that he "read it loudly, edit it and give it to someone to edit'(Tshepo).

Though the respondents highlighted that they apply these revising strategies, this is not the case in real practice as the tutors and marked assignments indicated the opposite. So, very few good students might be employing these

2 Language errors were taken as they were from their questionnaire responses and were not corrected 
strategies, particularly those who performed well with little or no grammar mistakes at all. Once more grammar emerges as an important aspect of writing by these ESL students. This corroborates with findings from other studies where ESL students desire to have a perfect grammar (Mojica 2010).

It is interesting to note that somehow students have an idea of what good writing entails and yet fail to apply that in their essay writing. As mentioned earlier, perhaps this suggests that lecturers are doing very little to improve the quality of student writing and should get more involved in showing students how to write essays at university level (Gambell 1991) or that writing was introduced late in their language learning curriculum (Lennerberg 1967 in Brown 1994).

Participants were further asked on how good they were at writing essay assignments in English. Some students felt their writing skills were between fair and average while some felt they were poor. Only one student claimed to have excellent writing skills. Some respondents perceived themselves to have good writing skills while others felt they had average writing skills. Judging by looking at students' essays and their writing on the completed questionnaire, these ESL students had average writing skills.

The respondents thought that the English course (ENN103F) helps them to write well in other modules. In other words, students claimed they were able to write in discipline-specific courses due to the contribution made by the English module. For example, Samantha said: "Yes, especially in other subjects like philosophy where we write essays" and Mosima also said: Yes, in cause in Physics we are often asked to write reports after experiments". Similarly, Lesiba said: Yes, it is not in English were we write essays also on other modules and helps on the way we read and understand words". In addition, participants from the focus groups indicated that ENN103F module gives them the basics for writing in other courses.

Participants generally recognise the value provided by the EAP (English for Academic Purposes) course as it equips them with the academic literacies they need for other courses (Philosophy, Physics) where they write essays. From the interviews data, when we probed more on this question, some students felt this module really fulfils what it is intended to do as it teaches them conventions of academic writing as well as the ability to cite sources. As a result, the findings of this study clearly resonate with the academic literacies theory (Lea and Street 2006; 1998) in that students view their reading and writing within disciplines improving because of the contribution made by the EAP module.

The AL model does not only involve writing but also includes reading. Participants were probed on their reading habits and they indicated engagement in reading academic books as opposed to leisure reading. Some claimed that reading improves both vocabulary and spelling. However, their writing on the completed questionnaire showed a number of grammar mistakes, thus suggesting that they were not reaping the fruits of reading as they could not transfer that to their writing. For instance, Martha said: "Yes- it (EAP module) broadens your knowledge and vocabulary. The more things you know the more things you can talk about, the easier it is to write constructively. On the other hand, Karabo stated: "Yes of course, because subconsciously you pick up the correct grammar and spelling".

All these responses indicate that participants perceived reading to have a positive influence on their writing, thus resonating with previous studies (Rose 2004; Munro 2003; Hart 1995). Participants also indicated that reading improves their knowledge. Participants said this about the effects of reading : "...you get more ideas on different forms of writing" (Martin) and Kobela said: "Novels, motivational books because I needed to stimulate my brain and expand my general knowledge on things but currently I try to read academic material that will help my studies and education".

These responses indicate students' perceptions on the developmental nature of reading as it increases their knowledge.

Some participants indicated that they read for leisure purposes. As indicated by one of the respondents, the reading of Christian literature inspires and motivates him: "Motivational (lift up my spirit i.e. Joel Osteen), a book with quotes i.e. Shakespeare, the parable of a pipeline (life teachings), magazines, for entertainment and books for my studies" (Lebo). In addition, Stephanie said she reads: "Comic books. I love cartoons" while Andrew was interested in "Conspiracies (Dan Brown)/scientific documentary material, Thrillers... anything that will have me glued to the pages from page 1". These responses indicate that some respondents are reading for non-academic purposes and this is the most enriching type of reading. However, it seems like magazines and newspapers are not very enriching reading materials as students may be skimming and scanning and not involved in comprehensive and thoughtful reading.

Participants seem to be devoting more of their time on their academic books and less on leisure reading. Though they are reading, the problem might be with the quality of the materials (newspapers, magazines) they read. Students' writing (marked assignments and questionnaire responses) is so full of grammar mistakes that one wonders if they do consult and use their dictionaries despite some indicating that they were using dictionaries. Considering the amount of time given for them to complete assignments, it is unforgivable that their assignments had such gross spelling errors. If they do not use this opportunity in essay assignments, it will be inevitable for them to repeat these mistakes in exams 
where stakes are high and also not allowed to use dictionaries.

Some participants indicated that writing an essay is more challenging and frustrating when the topic is difficult to understand. This is illustrated by Salome when she said "It is when I don't understand the topic", while Martha argued that "the most difficult part when beginning to write an essay is if the topic is something you are not familiar about and you are not interested in". Though it is the responsibility of ESL practitioners to ensure that students understand writing instructions, this might also imply that students have limited vocabulary. Some students also indicated that they struggled with "gathering the right information"(Tebogo) and another student confessed that "I mainly struggle to get good information about the topics and sometimes I get myself confused as to how to put the pieces together" (Lucky).

To add, information gathering is one of the basic ways of introducing students to do research and considering the number of resources (internet, google, and library) available especially in this information era, citing reasons like these is inexcusable. Thus, this study refutes the assertion by Juricic (2006) who argues that teaching writing is difficult in this era. On the other hand, some students perceived themselves to have problems with argumentation. For example, one student claimed he had problems with "Finding or making argument concerning the topic" (Sammy) while another student commented that his problem was "where to start, when the topic is there do I start with yes, no I agree or disagree" (Lesiba). This finding supports Yong's (2010) and Adams' (2008) assertions that students have negative perceptions regarding argumentation and that argumentation is an important skill for both undergraduate and postgraduate experience for ESL students (Lloyd 2007). These responses indicate that ESL practitioners should incorporate this aspect in their pedagogy. Sometimes, students do not even know what an academic argument is and tend to misconstrue it to be an altercation between two people in a conversation.

All these themes represent areas which ESL students are struggling with and something should be done to address these issues. Some respondents indicated the incorporation of the writing process when writing essays. However, this does not mean they developed these skills from high school. It is possible that students learned about the writing process from the study guide for the EAP course. On the other hand, there might be some rare cases where students bring these skills with them from high school, particularly those from well resourced schools. Some participants indicated that they struggled with writing in English and gave a number of reasons including "I don't have good skills from high schools (Thandi) ...there are still areas I still need to improve but am not completely lost (Salome). In addition, one participant said "... really struggling, I don't know how to put everything into perspective (Jane). Another participant said "Because I not perfect in English" (Sammy) and Mosima indicated "I'm not good at English at all so I almost find everything to be difficult but not most difficult".

The issue of struggling with the English language just confirms that ESL students are at a disadvantage (Banda 2007). On the other hand, academic writing is not only a challenge to these ESL students, but to first language speakers as well (Spencer 2007). This is because academic writing is a discourse used in higher education and all students need to be apprenticed into it as they do not come with it from high school. Participants concede that they are really struggling to write and this is very important instead of being in denial. We believe that this acknowledgement of weaknesses in writing will spur the students to work hard in learning how to improve their writing.

As indicated earlier, the respondents rated their writing skills to be fair to average, thus implying that they admit that their writing skills need further development. On the other hand, one cannot be oblivious to the fact that they are ESL learners and perhaps indicate the need for mother-tongue instruction which is a contentious issue in the education circles today. However, for this to be achieved, it would take a tremendous effort to change negative attitudes about the use of African languages in education which are still prevailing in the South African society. Nevertheless, the proposition by the Higher Education Minister to have university students enrol for at least one African language might be a move to change these stereotypes.

Modelling was deemed by participants as one the strategies of effective teaching of writing. Some participants indicated that "when we are in the classes, the tutor should do many examples with us and at the end homeworks so that we can mark when meeting again" (Given), "work more on academic writing" (Esther) "one to one consultation with a marker or tutor (Tebogo) "Yes, but for me to be more adequate in knowing English; I also need more academic English support" (Karabo). One participant contended "give us some essay to write during our tutorial classes and correct us were (sic) we made mistake and stop saying they won't spoon-feed us". This student is apparently annoyed by what the tutor said about not spoon-feeding them. It must be noted that students are desperate for all the support they can get from tutorials. If they are told they will not be supported as expected they become despondent. Furthermore, this finding concurs with Zamel (1989), who argues that students need to be given more writing tasks for them to become better writers.

We support these responses as most of the time it is not clear what lecturers/tutors expect from student writing. 
Therefore, providing models and showing students how to write academic essays can be very useful to students. In most cases, lecturers or tutors will say that an essay should have an introduction, body and conclusion without explicitly showing the students how to approach these components. Though the study guide for ENN103F teaches on the introduction, the body and the conclusion, they are, however, not taught explicitly (Unisa 2002). During the focus group interviews students also felt they needed more writing activities that are being marked. In the EAP course, students write only one essay assignment and they strongly feel it is not enough.

Some students felt they need more writing tasks to improve their writing skills. For instance, Tom said "I think writing more and spelling checks", while Sarah saw the need to "attend more classes, given more assignments" and Lethabo also suggested "more written exercises and oral practices in study groups/tutorials". These comments are an indication that students are not given enough writing tasks to harness their writing skills (Wingate 2006; Cohen and Riel 1989). Perhaps this confirms that most writing in educational circles is directed to the teacher for evaluation purposes. Some researchers found that writing for a different audience improves student writing (Jurecic 2006). Until the monopoly of writing to the teacher for evaluation purposes is minimised, students are likely to experience writing difficulties.

The issue of grammar is a predominant theme that emerged from the data and marked assignment data as well as student writing as it manifested as they filled the questionnaire confirm this finding. Fregreau (1999) contended that tutors' obsession with grammar hurts the students. Similarly, students are also obsessed with their grammar mistakes and it seems like perfect grammar is an unattainable skill for them.

\section{Recommendations}

Guided by the findings revealed in this study, we offer the recommendations in the following subsection.

\subsection{Intensive training of tutors/teachers}

Tutors should undergo rigorous and continuous training so that they can be fully equipped with the necessary skills for assessing students' work (Spencer 2007). Unless there is a radical change to the current practices, students will continue to get a raw deal from the university. Similarly, at school level, teachers should be trained adequately so that they should implement the effective teaching of writing and not just spend more time on administrative work. They should undergo continuous professional development in the form of in-service training and also given incentives to further their ESL studies.

\subsection{More tutor-lecturer interaction}

There is a disjuncture between what lecturers and tutors expect from students. In most cases, tutors do not know what lecturers expect from students and that creates confusion to students. To avoid confusing and contradictory messages to students, these two ESL practitioners should communicate more frequently, particularly in the ODL context.

\subsection{Academic Literacies Centres}

The Academic Literacies Centres or Writing Centres are very crucial in addressing academic writing issues that students are struggling with. Unfortunately, these critical services are often treated as peripheral services in the academia. In most cases, these services do not have permanent staff members and quality cannot be sustained as experienced facilitators are normally snatched by other departments who offer them full-time employment (Ivanic` \& Lea 2006; Lillis 2001). If the academia is serious about addressing issues of academic literacies, then these services will have to be mainstreamed. Maloney (2003:665) points out that academic literacy require students to synthesise and analyse text, demands them to read and write the texts competently and persuasively. He reports that throughput rates improved dramatically as a result of changing the approach in the compensatory literacy programme implemented on at-risk first year college students.

\subsection{Typing of written assignments}

Though students will be expected to use hand writing in the exams, we suggest that students should be encouraged to hand in typed assignments. This is relevant because we live in a technologically-oriented era where students are encouraged to use online learning management systems to learn and to submit assignments. Probably, this might 
eliminate a number of grammar errors through the help of spell-check function on the computer and help ESL students to develop their spelling in the process. Research also confirms that word processing is useful in language learning as it reduces the mistakes (Dam, Legenshausen \& Wolff, 1990; Kellogg 1994 in Appel and Mullen 2000). This might help markers to give more comments on content (academic writing) than on surface grammar features.

\subsection{Editing of written assignments}

Post-graduate dissertations and theses are taken for language editing before being submitted to supervisors or examiners. However, this is not encouraged at undergraduate level, particularly at first year level. Therefore, we suggest that language editing should also be extended to first year levels where it is needed the most. As much as excellence is encouraged at post-graduate level, this should also build up from undergraduate level and this will help in focusing more on academic literacies than on surface grammar features when evaluating student writing. Though Academic Literacies Centres do not endorse language editing to be incorporated as part of their interventions (Bharuthram and McKenna 2006), this is a crucial service that should be incorporated at undergraduate level.

\section{Conclusion}

On the whole, the study shows that both students and tutors face numerous challenges relating to academic writing at first year level. This means that more work still needs to be done in this area. The study argues that tutors and lecturers teaching first year students should also be equipped to teach academic writing to address students' specific needs. However, the challenges relating to student writing will continue being a problem at first year level unless institutions of higher learning start addressing academic writing, particularly in ESL contexts as a critical and core component of students' academic development and the study has unearthed some of the pertinent challenges.

\section{References}

Appel, C. and T. Mullen, (2000). Pedagogical considerations for a web-based tandem language learning environment, Computers and Education (34), 291-308.

Bharuthram, S and McKenna, S. (2006). A writer-respondent intervention as a means of developing academic literacy. Teaching in Higher Education, 11, (4), 495-507.

Cliff, A and Hanslo, M, (2009). The design and use of alternate assessments of academic literacy as selection mechanisms in higher education. Southern African Linguistics and Applied Language Studies, 27, (3). 265-276.

Granville, S. and Dison, L., (2009). Making connections through reflection: writing and feedback in an academic literacy programme. Southern African Linguistics and Applied Language Studies, 27, (1), 53-63.

Hirst, E, Henderson, R, Alan, M, Bode, J. \& Kocatepe, M. (2004). Repositioning academic literacy: Charting the emergence of a community of practice. Australian Journal of Language and Literacy, 27, (1), 66-80.

http://www.news24.com/SouthAfrica /Politics/Hearings-into-school-curriculums-20090630. Accessed on 30 June 2009.

http://www.learnhigher.ac.uk/resources/files/Academic\%20Writing/academic_writing_literature.pdf. Accessed on 06 May 2009.

Ivanic, R. \& Lea, M.R. (2006). New contexts, new challenges: the teaching of writing in UK

Higher Education. In L. Ganobcsik-Williams (Ed.) Teaching Academic Writing in UK Higher Education: Theories, Practices and Models, (pp. 66-85) New York Palgrave, Macmillan.

Jacobs, C. (2005). On being an insider on the outside: new spaces for integrating academic literacies. Teaching in Higher Education, 10, (4), 475-487.

Jurecic, A. (2006). Is Teaching Writing Still Possible? New Jersey Writing Alliance. [Online]Available from: http://www2.bergen.edu /njwa/NJWA_2006_materials_jurecic.pdf Accessed on 03 March 2011.

Lafaye, B. E. \& Tsuda, S. (2002). Attitudes towards English Language Learning in Higher Education in Japan and the Place of English in a Japanese Society. Intercultural Communication Studies, 11, (3), 145-161.

Lamberg, W.J. (1977). Major Problems in Doing Academic Writing, College Composition and Communication, 28, (1), 26-29.

Lea, M.R. (2004). Academic Literacies: a pedagogy for course design. Studies in Higher Education, 29, (6), 739-756.

Lea, M. R. \& Street, B.V. (2006). The "Academic Literacies" Model: Theory and Applications. Theory into Practice, Vol. 45, (4), 368-377.

Lea, M.R. \& Street, B.V.(1998). Student Writing in Higher Education: an academic literacies approach. Studies in Higher Education, 23 (2), 157-172.

Lillis, T. (2001). Student Writing: Access, Regulation, Desire. New York, Routledge.

Lillis, T. (2003). Student Writing as 'Academic Literacies': Drawing on Bhaktin to Move from Critique to Design. Language and Education, 17, (3), 192-207.

Lillis, T. (2006). Moving towards 'Academic Literacies' Pedagogy: Dialogues of Participation. In L. Ganobcsik-Williams (Ed) Teaching 
Academic Writing in UK Higher Education: Theories, Practices and Models, (pp. 86-100) New York, Palgrave Macmillan.

Lillis, T. \& Scott, M. (2007). Defining Academic Literacies Research: Issues of epistemology, ideology and strategy. Journal of Applied Linguistics, 4, (1), 5-32.

Lloyd, M. (2007). Developing academic writing skills: the PROCESS framework, Nursing Standard, 21, (40), 50-56.

Maloney, W. H. (2003). Connecting the texts of their lives to academic literacy: Creating success for at-risk first year college students. Journal of Adolescent \& Adult Literacy, 46, (8), 664-673.

Moutlana, I.N. (2007). Challenges facing higher education: The problem of Academic Literacy, VC/Speeches/ North West University Workshop-17 September 2007.

Motlanthe, Kgalema, Speech presented at the Higher Education Summit, Bellville, Cape Town, 22 April 2010.

Munro, J. (2003). Fostering Literacy Across the Curriculum. International Journal of Learning, 10,327-336.

Niven, P.M. (2005). Exploring first year students' and their lecturers' constructions of what it means to read in the humanities discipline: a conflict of frames? South African Journal of Higher Education 19, (4), 777-789.

Nunan, D. (1990). 'Using Learner Data in Curriculum Development'. English for Specific Purposes, 9, 17-32.

Rose, D. (2004).Sequencing and pacing of the hidden curriculum: How indigenous children are left out of the chain? In J. Muller, A. Morais \& B. Davies (Eds.) Reading Bernstein, Researching Bernstein. (pp.105-120) London: Routledge Falmer.

Saddler, B., Moran, S., Graham, S. \& Harris, R.(2004). Preventing Writing Difficulties: The Effects of Planning Strategy Instruction on the Writing Performance of Struggling Writers, Exceptionality, 12, (1), 3-17.

Scott, I. (2006). Improving first year student success: models and structures. Unpublished document produced for the Coordinating Committee of the Stellenbosch University First Year Academy Initiative. Cape Town.

Spencer, B. (2007). Towards greater equality: Power and role relations involved in response to student writing. Language Matters: Studies in the Languages of Africa, 38. (2), 299-315.

Unisa, 2002. Only study guide for ENN103 (English for Specific Purposes), Muckleneuck, Pretoria, Unisa.

Van Rensberg, W. \& Lamberti, P. (2004). The language of learning and teaching. In Gravett, S. and Geyser, H.C. (Eds). Teaching and learning in higher education. (pp. 108-125) Pretoria: van Schaik Publishers.

Van Schalkwyk, B. \& Van der Walt, E. (2009). Acquiring academic literacy: a case of first year extended degree programme students. Southern African Linguistics and Applied Language Studies, 27, (2), 189-201.

Wingate, U. (2006). Doing away with the study skills, Teaching in Higher Education, 11, (4), 457-469.

Wright, S. A. (2004). Perceptions and stereotypes of ESL students, The Internet TESL Journal, Vol.10, No.2 February 2004. [Online]Available from: http://iteslj.org/Articles/Wright-Stereotyping.html. Accessed on 18 January 2009.

Yong, F.L. (2010). Attitudes toward academic writing of foundation students at an Australian-based university in Sarawak, European Journal of Social Sciences, 13. (2), $472-478$.

Zamel, V. (1987). Recent Research on Writing Pedagogy, TESOL Quarterly, 21, (4), 697-715. 
